\title{
Keeping rail on track: preliminary findings on safety culture in Australian rail
}

\author{
Verna Blewett ${ }^{\mathrm{a},}$,, Sophia Rainbird ${ }^{\mathrm{a}}$, Jill Dorrian ${ }^{\mathrm{b}}$, Jessica Paterson ${ }^{\mathrm{a}}$ and Marcus Cattani \\ ${ }^{a}$ Appleton Institute, Central Queensland University, 44 Greenhill Rd, Wayville, South Australia 5034, Australia \\ ${ }^{\mathrm{b}}$ School of Psychology, University of South Australia, GPO Box 2447, Adelaide, South Australia 5001, Australia \\ ${ }^{\circ}$ Cattani Consulting Pty Ltd, 44 Redwood Crescent, Melville, Western Australia 6156, Australia
}

\begin{abstract}
Safety culture' is identified in the literature as a critical element of healthy and safe workplaces. How can rail organizations ensure that consistently effective work health and safety cultures are maintained across the diversity of their operations? This paper reports on research that is currently underway in the Australian rail industry aimed at producing a Model of Best Practice in Safety Culture for the industry. Located in rail organizations dedicated to the mining industry as well as urban rail and national freight operations, the research examines the constructs of organizational culture that impact on the development and maintenance of healthy and safe workplaces. The research uses a multi-method approach incorporating quantitative (survey) and qualitative (focus groups, interviews and document analysis) methods along with a participative process to identify interventions to improve the organization and develop plans for their implementation. The research uses as its analytical framework the 10 Platinum Rules, from the findings of earlier research in the New South Wales (Australia) mining industry, Digging Deeper. Data collection is underway at the time of writing and preliminary findings are presented at this stage. The research method may be adapted for use as a form of organizational review of safety and health in organizational culture.
\end{abstract}

Keywords: rail safety, multi-method research, organizational culture, safety culture, keyword five

\section{Introduction}

For the improvement of work health and safety, a key strategic issue is attention to those cultural features of organizations that are concerned with achieving healthy and safe workplaces. 'Safety culture' may be a useful short-hand term for these aspects of organizational culture. It is identified in the literature as a critical element of healthy and safe workplaces [18] and defined as an intrinsic quality of an organization, based on its values, attitudes and behaviors [11] that are related to the development and maintenance of healthy and safe workplaces. However, there continues to be debate about the definition of this construct and its relationship to safety performance. As Hopkins puts it, "safety culture is an attractive idea... it is not, however, a straightforward idea" [7].

There is considerable organizational effort being spent on managing safety culture and organizational culture, effort that may well be misplaced. Hatch and
Cunliffe [6] warn that although it might be reasonable to be concerned about organizational culture, trying to interfere with it can have unpredictable outcomes. Instead they advise that we,

... need to give up thinking of culture as an entity and [try] to understand what it does ... think of culture as a context for meaning making and interpretation [6].

Antonsen suggests that, "organizational cultures are produced locally, and ... managers cannot expect to be able to shape organizational culture at their discretion" [2]. Rather than attempting to manage culture the diversity of views that make up an organization's culture and sub-cultures should be considered and valued. Regardless of the change that is introduced in an organization there will be multiple interpretations of the actions that are taken that will represent the multiplicity of views that exist in the organization. Instead of trying to manage people's views, which is bound to be unsuccessful, taking

*Associate Professor Verna Blewett. E-mail: v.blewett@cqu.edu.au 
those views and interpretations into account in the design and implementation phases of organizational change is likely to reap rewards. By allowing the variety of opinion to persist and develop in an organization, many points of view can be effectively brought together to deal with problems, challenges and daily organizational frustrations. There is a greater likelihood that the resulting decisions will be more full and capable of implementation because they do not deny difference, but incorporate it [16].

How does this apply to the rail industry? There are regulatory, moral and business imperatives in conducting rail transport in a healthy and safe manner in Australia. These influences operate across organizations, but may be expressed differently in the different sub-cultures that make up the organization. For example, rail drivers, on-train staff, security staff, maintenance crews, track workers and contractors may each have different and distinctive sub-cultures. How then, can rail companies ensure that consistently effective workplace health and safety cultures are maintained across the diversity of their operations?

\subsection{Current research}

The research reported in this paper is currently underway in the Australian rail industry and is scheduled for completion in June 2012. It is located in three rail organizations dedicated to the mining industry as well as urban rail and national freight operations. At the time of writing, each organization is at a different stage in the data collection and analysis.

The broad objectives of the research are to:

- Build a Model of Best Practice Safety Culture for the Australian Rail Industry.

- Test the ability of the UK Rail Safety and Standards Board (RSSB) Safety Culture Survey as an instrument that is able to indicate progression towards best practice safety culture.

- Test the 10 Platinum Rules from the Digging Deeper project [13] as a framework for action towards best practice in the Australian rail industry.

- Identify improvements in the Safety Culture Survey that better enable its use as an assessment of best practice safety culture.

- Identify what organizations can do in response to identified gaps in safety culture, that is, how they can address the gaps.

The importance of this research for the Australian rail industry is that it draws on the experience of the industry itself in its pursuit of best practice. It also builds on the evidentiary base for best practice principles for health and safety provided by another high hazard industry and one that intersects with rail, that is, mining. The use of the findings from Digging Deeper and its multi-method, evaluative approach provides reliable data that leads to improvement in participating organizations that may be extrapolated throughout the industry. This is more complex than a simple audit approach, but does not have the same drawbacks as a reliance on auditing [3].

\subsection{The case-study organization}

This paper is confined to one of the enterprises participating in this research, a mining firm that has its own $300 \mathrm{~km}$ rail track located in the remote Pilbara region in north-western Australia. The rail operations of this enterprise consist of a dedicated heavy haul rail line, loading and unloading facilities, and rolling stock that transports iron ore from the inland mining operation to the port operation located at Port Hedland. About 130,000 tonnes of ore are mined each day. The firm employs approximately 330 people in non-mining activities: 140 at the port, 150 in rail, and 40 in rail maintenance. A small proportion of the workforce lives in Port Hedland but the majority of employees fly-in and fly-out (FIFO) from Perth, approximately 2 hours by plane. A further 2,500 people are employed at the mine site and these people, too, are largely employed as FIFO workers. This is an organization undergoing significant growth, but like others in the Australian mining industry, it faces an acute skills shortage, exacerbated by the difficulties of isolation and extreme weather conditions.

\section{Method}

\subsection{A multi-method approach}

The research uses a multi-method approach incorporating quantitative (survey) and qualitative (focus groups, interviews and document analysis) methods along with an innovative participative process to identify interventions to improve the organization and develop plans for their implementation. Multimethod research has a long history [5]; it is a tried and tested means of obtaining convergent data that allows triangulation to increase certainty, as well as divergent data that encourages further questioning and investigation. Different views on aspects of the 
data allow us to be confident that what we see in the data reflects reality and not methodological error [10].

Ethics approval for this research was obtained from the University of South Australia's Human Research Ethics Committee.

\subsection{Quantitative data}

The survey used is the Safety Culture Survey of the UK Rail Safety \& Standards Board (UK RSSB), adapted for Australian use, with analysis of results undertaken by the research team. We have selected this tool because it has been made freely available to the Australian rail industry by the Australian Rail Industry Safety and Standards Board (RISSB) and its use is growing in the industry. This voluntary and anonymous survey contains 61, 5-point, Likert-scale items that examine the cultural factors: barriers and influences, training, communication, organizational commitment, management commitment, supervisor's role, personal role, workmates' influence, risk-taking behaviors, employee participation, and organizational learning [1]. The demographic questions in the survey are modified for each participating organization to take account of differing organizational structures and job titles, but will be normalized across the whole data set. The survey yields quantitative data about each of the factors. The survey was administered in hard copy and online versions in the participating organization in April 2011 and a second, follow-up round of survey administration is scheduled for December 2011 - January 2012. The data are being statistically analyzed using standard statistical tests, including factor analysis and Cronbach's Alpha to test internal consistency. We have high response rates suggesting that we will have significance in our results and these will be reported as they come to hand. About $10 \%$ of respondents included comments in the free text question, which will be analyzed with other qualitative data.

\subsection{Qualitative data}

Qualitative data provide a richness that is unable to be extracted from quantitative data. They consist of the stories, anecdotes, examples, and opinions that people are willing to share with us. These data are collected in a variety of ways. Focus group and interview schedules were developed from the findings of the survey and separately engage six key categories of people in participating organizations: senior management, line management, workers, workplace health and safety professionals, worker health and safety representatives (who have mandated rights in Australian OHS law), and workplace health and safety committee members. These data are combined with the free text field from the survey. Combining the written qualitative data from the surveys with the focus group and interview data enables the sources of qualitative data to be expanded to include anonymous participants. This helps to increase the population of people contributing to the qualitative data and provides improved confidentiality. Document analysis is refined for each organization depending on its size and jurisdictional location. Australia currently has ten jurisdictions for workplace health and safety legislation. Whilst these are similar in nature, they have different requirements and impose different tests on duty holders.

\subsection{Participatory process}

The participative process used is Future Inquiry [4] based on the principles of Appreciative Inquiry [17] and Future Search [16].

In the context of this research, the workshop is used to give participating organizations the opportunity to determine its response to the findings of the first part of the research (survey, focus groups and interviews) and participatively develop action plans for interventions that will make a difference to workplace health and safety, which in turn may lead to improvements in safety culture. Typically the outcomes of such participatory workshops is to develop multiple means of improving workplace health and safety (technical, organizational and procedural), assign priority to those efforts and produce the first steps of an action plan to make them happen. This is consistent with a defense-in-depth approach to workplace health and safety, providing multiple lines of defense rather than relying on a single protective element such as a focus on worker behavior [12].

Analysis of the qualitative data is conducted using a manual process of reviewing and tabulating all of our interview notes and recordings and the comments in the free text field of the surveys to identify key themes and conceptual groupings [8, 14]. The first pass analysis compares the free text material to the RSSB factors and a second pass analysis compares all of our data (quantitative and qualitative) to the 10 Platinum Rules of Digging Deeper [13] to identify the applicability of mining health and safety models to the rail industry. That is we use the 10 Platinum Rules as an analytical framework. 


\subsection{Confidentiality}

Confidentiality is a foundation consideration in this project. We take a number of steps to ensure that the identity of individuals who provided information to us is kept private. This is particularly important given the organizations that are participating in the research will be named as participants in the research, are known to each other and known in the rail industry.

During our site visits, all participants are assured of the confidentiality of the information collected. Site visits are undertaken on the ethical basis that participants give informed consent to participate in surveys, interviews and focus groups and that they give information on the basis that they will not be identified, and that no harm will come to them arising from the project [9].

In reporting our quantitative and qualitative data we only report on groups that contain more than 15 members to make identification more difficult. This means that sometimes we conflate data between like groups to protect identities and may be unable to report on sub-groups in the organization. We do this rather than risk the confidentiality of participants. To further protect individuals, where people have been quoted we sometimes alter the wording so as not to lose meaning or information, but to prevent identification.

\section{Preliminary findings}

At the time of writing the first survey has been completed in the organization and the data analyzed. Collection of qualitative data on site was underway during the preparation of this paper. There was a response rate of $56 \%$ to the survey with a total of 184 responses (from a population of $\mathrm{N}=330$ ). Interestingly, 147 of these were hard copy versions with only 37 online versions being received, reflecting the predominantly out-of-office nature of the workforce. Twothirds of respondents were from the rail part of the business, with the remainder from the port, which is the final destination of the rail line.

Even at this early stage, the first round survey, focus groups and interviews (at another site) appear to be identifying gaps in the RSSB survey when used in
Australian conditions. In particular, factors about work demand (physical, emotional or cognitive) are missing from the survey in its present form, but are a theme that is evident in the qualitative data of the free text question. Internal consistency was assessed for each dimension using Cronbach's Alpha (Table 1). Higher alpha values indicate higher levels of consistency between the items that load onto that dimension. Dimensions with alpha values greater than 0.70 are considered to have adequate consistency between items. Two dimensions had poor internal consistency: management commitment and risktaking behaviors. Modifications to these dimensions will be considered for the next iteration of the survey.

\section{Using the 10 Platinum Rules}

The Digging Deeper study [13] demonstrated that sites need the capacity to develop their own systematic approaches to the management of OHS that reflect their unique needs, and they must be capable of assessing that these approaches actually meet organizational needs. This is more effective in achieving high performance in OHS than adopting prescriptive rules that may indeed prevent reflexive, improvement-oriented approaches to OHS management. The 10 Platinum Rules, summarized below, are drawn from the experience of the Australian mining industry and codify the steps to best practice in OHS [13].

Rule 1. Remember you are working with people. The first Platinum Rule describes the need for a culture of respect that permeates the organization. It means everyone treating everyone else with respect, regardless of their status in the organization; it's a two-way street. This is simple in theory, but often difficult to generate and maintain in practice. It requires persistence and gumption, especially when efforts to generate such a culture go against the grain of accepted practice.

Rule 2. Listen to and talk with your people. Rule 2 emphasizes the importance of consultation and workforce participation in decision-making as a means of making the workplace healthy and safe. Using the valuable information of employees is costeffective, efficient and good management practice. 
Table 1.

Internal consistency of dimensions. Alpha of approximately 0.7 is considered adequate.

\begin{tabular}{lll}
\hline Dimension & $\begin{array}{l}\text { Consistency (Cronbach's } \\
\text { Alpha) }\end{array}$ & $\begin{array}{l}\text { Consistency } \\
\text { (final) }\end{array}$ \\
\hline Barriers and influences & 0.620 & 0.620 \\
\hline Training & 0.740 & 0.740 \\
\hline Communication & 0.780 & 0.780 \\
\hline Organizational Commitment & 0.801 & 0.801 \\
\hline Management commitment & 0.599 & - \\
\hline Supervisor's Role & 0.757 & 0.757 \\
\hline Personal Role & 0.459 & 0.646 \\
\hline Work Mate's Influence & 0.741 & 0.741 \\
\hline Risk Taking Behaviors & 0.584 & - \\
\hline Participation and Involvement & 0.775 & 0.775 \\
\hline Organizational Learning & 0.665 & 0.707 \\
\hline
\end{tabular}

Effective consultation requires the willingness of employees to participate, but it also needs encouragement by management to make it happen. It requires workers and management being able to hold respectful conversations, even about matters that are difficult. It means having a mix of formal and informal consultative processes that engages the diversity in the workforce; including shift-workers and parttimers who may have specific and unique needs. Effective consultation helps build mutual trust and respect.

Rule 3. Fix things promptly. Poor communication influences performance against Rule 3. When people make complaints, or otherwise bring things to the attention of management, getting a fast response means the reporter is rewarded with action and the workplace is improved. Even if the issue isn't fixed straight away, giving the reporter information about progress lets them know that the matter is important and their contribution is valued. On the other hand, giving no response is an effective way to build cynicism and undermine trust.

Rule 4. Make sure your paperwork is worth having. There are documents that are essential to maintain to ensure compliance with the law, to set boundaries, to be clear about rules that need to be obeyed, to report on progress, and to assist planning. In fact, there are considerable demands placed on organizations to maintain records that make it clear that action is being taken to improve workplace health and safety. Whatever records an organization deems it must have, regular review of those records is imperative to stop wasted time and effort, because this may divert attention from matters that need effort. Records need to be current, meaningful and they should contribute to keeping the workplace healthy and safe. If they don't meet these criteria, then they may not be worth having

Rule 5. Improve competence in OHS. Competence in OHS, particularly at management levels, is crucial to a safe and healthy workplace and workplace culture. Competence in OHS at management levels contributes to employees' understanding of management commitment, this helps to improve trust, which in turn contributes to an organizational culture that is judged fair and effective with respect to health and safety. Managers who know what they are talking about in health and safety are also able to engage good people to give them advice, they can adequately assess if the advice they are given is good or not, and they put workplace health and safety on the list of things to consider when making decisions about the organization. When it's the workers' health and safety representative who knows most about OHS in the workplace, then management may be at a distinct disadvantage and conflict may be the result.

Rule 6. Encourage people to give you bad news. This rule highlights the importance of noticing when things are wrong and reporting them to someone who can do something about it. That is, workers should be encouraged to report bad news. Workers at the front line are most able to provide information about what works and what doesn't because they are at the front-line every day and have experiences that enable 
careful reporting. This rule encourages management to engage with the skeptics and cynics in the organization because it's these people who are entrepreneurial enough to be prepared to 'stick their neck out' and say what they think. Sometimes they are not the easiest people to deal with, so giving them training can be key to harnessing their energy.

Rule 7. Fix your workplace first. Many organizations are quick to take up the latest fashionable "program du jour" as a means of making the workplace healthy and safe. This rule assert that it's necessary to go back to the basics; that the only way to make a workplace healthy and safe if to take the action necessary to make it healthy and safe. If the workplace is in poor condition or uses poorly designed work processes, then buying in the latest safety system is unlikely to be effective. This particularly applies to add-ons such as "behavior-based safety" systems, and "well-being" programs.

Rule 8. Measure and monitor risks that people are exposed to. Controlling risks at source is vital, but how can you predict when or if a hazard is something to be concerned about? Measuring or assessing exposure is a crucial element in this. Knowing what exposures exist in the workplace makes if more likely that they will be controlled, too. Relying on worker behavior to control risks will always fail, sooner or later, because we all make mistakes.

Rule 9. Keep checking that what you are doing is working effectively. Being busy is not the same as being effective. A well-designed assessment process can identify progress in OHS and is a crucial part of a healthy and safe workplace. Constant monitoring enables small adjustments to be made that keep the OHS machine well-oiled and on the track.

Rule 10. Apply adequate resources in time and money. This rule demands a commitment of time and money to improvement in health and safety. It costs money to make a workplace healthy and safe. There may be a return on investment in terms of turnover or in health and safety terms, but sometimes it's just necessary to make the expenditure to make the workplace healthy and safe in order to do the work at all.

\section{Conclusion}

Our multi-method approach to this research provides us with varied sources of data that give robust and reliable findings. Such an approach to determining OHS performance and assessing an organiza- tion's safety culture provides sufficient data to enable the participative development of interventions to improve the workplace. Whilst the traditional means of assessment, auditing, has value, it also has significant drawbacks and lacks a future improvement focus. We believe our evaluative method could be used as a means of review of organizational culture, particularly with respect to safety.

\section{Acknowledgements}

We acknowledge the assistance from the following: the Cooperative Research Centre for Rail Innovation for support and research funding; the case study organization for travel support as well access for the research personnel to sites, personnel and data; the case study organization's employees and contractors for their willing participation in this research.

\section{References}

[1] P. Ackroyd, RSSB Safety Culture Toolkit Project Final Report T397, London, UK, Rail Safety and Standards Board Ltd (2007).

[2] S. Antonsen, (2009). Safety culture and the issue of power. Safety Science 47(183-191).

[3] Blewett, V. and V. O'Keeffe (2011). Weighing the pig never made it heavier: Auditing OHS, social auditing as verification of process in Australia. Safety Science 49: 10141021

[4] Blewett, V. and A. Shaw (2008). Future Inquiry: participatory ergonomics at work. Ergonomics is a Lifestyle, Reykjavík, Iceland, Nordic Ergonomics Society.

[5] Brewer, J. and A. Hunter (1989). Multimethod research: a synthesis of styles. Newbury Park, Sage.

[6] Hatch, M. J. and A. L. Cunliffe (2006). Organization theory: modern, symbolic and postmodern perspectives. New York, Oxford University Press: 235 - original emphasis.

[7] Hopkins, A. (2002). Safety, culture, mindfulness and safe behaviour: Converging ideas. National Research Centre for OHS Regulation Working Paper 7: 14.

[8] Huberman, M. A. and M. B. Miles (1994). Data management and analysis methods. Handbook of qualitative research. N. K. Denzin and Y. S. Lincoln. Thousand Oaks, Sage: $209-219$.

[9] Kellehear, A. (1989). Ethics and social research. Doing fieldwork: eight personal accounts of social research. J. Perry. Melbourne, Deakin University Press: 61-72: 63.

[10] Maxwell, J. (2005). Qualitative research design: An interactive approach. Thousand Oaks, Sage Publications.

[11] Richter, A. and C. Koch (2004). Integration, Differentiation and Ambiguity in Safety Cultures. Safety Science 42: $703-$ 722.

[12] Saleh, J. H. and A. M. Cummings (2011). Safety in the mining industry and the unfinished legacy of mining accidents: Safety levers and defense-in-depth for addressing mining hazards. Safety Science 49: 764-777. 
[13] Shaw, A., V. Blewett, et al. (2008). Digging Deeper: Wran Consultancy Project Final Report. Volume 1. Sydney, NSW Mine Safety Advisory Council.

[14] Strauss, A. (1987). Qualitative analysis for social scientists. Cambridge, Cambridge University Press.

[15] Weisbord, M. (1987). Productive workplaces revisited: Dignity, meaning, and community in the 21 st Century. San Francisco, Jossey-Bass.

[16] Weisbord, M. R. and S. Janoff (2000). Future search: an action guide to finding common ground in organizations and communities. San Francisco, Berrett-Koehler.
[17] Whitney, D. and D. Cooperrider (1998). The appreciative inquiry summit: overview and applications. Employment Relations Today 25(2): 17-28.

[18] Zohar, D. (2010). Thirty years of safety climate research: Reflections and future directions. Accident Analysis and Prevention 42: 1517-1522. 